\title{
CONSTRUCCIONES CAUSALES CON GERUNDIO EN CASTELLANO MEDIEVAL
}

\author{
Josefa $M^{a}$ Mendoza Abreu
}

No hay unanimidad de criterio entre los lingüistas a la hora de definir el gerundio ni como forma (con frecuencia se califica como forma mixta entre la categoría nominal y verbal; forma impersonal, forma finita, etc.), ni tampoco en lo que respecta a sus funciones (adjetivo, adverbio, etc.) y usos ${ }^{1}$, y ello, quizás, porque se parte de sincronías diferentes, y estamos ante uno de los elementos que más ha cambiado a lo largo del tiempo, incluyendo el propio latín ${ }^{2}$. Además, a veces se confunden, o al menos se utilizan como sinónimos valor e incluso forma y función. Sin embargo, el hecho de que en ciertas estructuras coincida la función del gerundio con la de un adverbio no quiere decir que el gerundio se convierta formalmente en un adverbio, sino que ambos pueden realizar la misma función sintáctica. ${ }^{3}$

En este sentido, no ofrece dudas que el gerundio en español, y en las otras lenguas románicas, en general, puede cumplir dos funciones fundamentales o, como señala Lyer (1932: 1), puede realizar las funciones de dos formas latinas, la del ablativo de gerundio y la del participio de presente: "Le geronfif en espagnol, comme d'ailleurs dans toutes les langues romanes, remplit les fonctions de deux formes verbales latines: celle du gerondif et celle du participe présent". Aunque es la primera la que ahora nos interesa: "Il retient la valeur primitive du gérondif latin -ndo là où il complète le verbe principal au point de vue adverbial, en indiquant l'instrument, le moyen ou la manière avec laquelle l'action principale se réalise.”. Señala además Bassols (1981: 400) que el gerundio en ablativo sin preposición, en su acepción instrumental, era frecuente en el latín arcaico, pero casi siempre con un "matiz causal" y dependiendo de verbos que expresan una idea de cansancio o fatiga. Los ejemplos clásicos ofrecen casi todos un significado instrumental, si bien en el

1 Andrés Bello (1970, \& 42) lo define como un derivado verbal que hace el oficio de adverbio; pero las mayores aportaciones que encontramos en esta Gramática en cuanto a significados y usos del gerundio están en la nota 72 de R. J. Cuervo (procedentes en parte de Bello y también de R. Ángel de la Peña), donde se hallan las bases de la mayor parte de las teorías que aparecen en las gramáticas posteriores (Gili y Gaya, 1978; RAE, 1976; etc).

${ }^{2}$ Ya en el latín tardío el gerundio en ablativo empezó a sustituir al participio de presente; estos cambios continúan en el romance desde los primeros tiempos, de manera que ya en las Glosas Emilianenses y Silenses el gerundio sustituye al participio de presente: ignorate: non sapiendo, Gl. Sil. 32 (Bastardas Parera, 1951: 175; Bassols, 1981: 399; Lyer, 1934; Bobes Naves, 1975: 2; Muñio, 1995: 12; etc. ). Para el español moderno vid. Hallebeek (1998) y bibliografía allí citada.

${ }^{3}$ Vid. , entre otros, Bobes Naves (1975); Hallebeek (1998). 
latín decadente prevalecería el matíz modal, al menos en los textos escritos. Y ese parece ser también el más común en castellano ${ }^{4}$.

En cualquier caso, y como forma perteneciente al paradigma verbal (aunque carezca de modo, persona, etc. $)^{5}$ el gerundio puede funcionar como núcleo verbal oracional $\mathrm{y}$, consiguientemente, puede indicar relaciones circunstanciales de lo expresado en el verbo personal, relaciones que pueden variar, desde el punto de vista semántico, en cuanto a los significados modal, causal, concesivo, etc. Pero además, y precisamente por ser forma invariable (simple o compuesto), los diferentes significados, al igual que las relaciones temporales de una proposición de gerundio sólo pueden deducirse de la información aportada por otros elementos que, generalmente, se encuentran en la "oración principal", por lo que esas relaciones no siempre son todo lo nítidas que desearíamos.

Como forma para expresar las relaciones de causalidad, el gerundio ha sido utilizado en el español de todos los tiempos. Sin embargo, no parece que siempre haya tenido la misma vitalidad $^{6}$.

Nuestro propósito en este trabajo es comprobar los diferentes usos y variantes que las oraciones causales con gerundio presentan en textos no literarios del castellano medieval ${ }^{7}$, y su comparación con las introducidas a través del sistema de conjunciones. Es decir, si se utiliza para el mismo tipo de causa ${ }^{8}$ a aparece en las mismas posiciones o presentan algunas

4 Así, por ejemplo, para la RAE (1976: 489), Gutiérrez Araus (1978: 223-224), etc. Aunque el más estudiado y discutido sea el temporal, sobre todo el de posterioridad, por los problemas de "corrección" gramatical que para algunos autores (desde Bello) plantea (Bouzet, 1953; Badía, 1964). No ocurre así con el causal, pues en este caso (como sucede con algunas conjunciones temporales que adquirieron valor causal) se aplica generalmente el viejo principio post hoc ego propter hoc.

${ }^{5}$ Como acertadamente señala Gutiérrez Araus (1978: 224), al igual que Bouzet, el gerundio español es una forma verbal impersonal y atemporal en cuanto hecho de lengua; pero en el habla se inscribe en la perspectiva temporal de la frase y puede ir acompañado de sujeto y de complementos.

6 Así, por ejemplo, en el Poema de Mio Cid aparece un único ejemplo (versos 1890-92), citado por Kretschmann (1936: 78) y por Mosteiro Louzao (1998: 285). El citado por Lyer (1934: 109) no tiene tal significado.

7 Para ello hemos elegido el mismo corpus que hace ya tiempo nos sirvió para el estudio del sistema conjuntivo causal en época medieval, la documentación medieval del Concejo de Écija (con transcripción y estudio paleográfico y diplomático realizado como Tesis Doctoral por la prof. $\mathrm{M}^{\mathrm{a}} \mathrm{J}$ Sanz Fuentes. Desde aquí, de nuevo mi sincero agradecimiento) Vid. J. Mendoza (1985).

8 Para esta cuestión seguimos la distinción comúnmente aceptada en los últimos tiempos, desde que D. Rafael Lapesa, apoyando los criterios de Bello, habló de dos tipos de subordinación causal, y fijó la denominación (dada a conocer por F. Marcos Marín, 1980: 392) de causales del enunciado y causales de la enunciación, correspondiente a las tradicionales causa real y causa lógica. Si bien hay algunos tipos que, al menos desde el punto de vista semántico no cuadran en ninguno de los dos (Santos, 1982; Mendoza, 1985), independientemente (o a pesar) de la modalidad verbal: "no toques el enchufe, porque (que) da calambre" y "no toques el enchufe porque (que) te pego", sintácticamente son iguales (hay un verbo de mandato implícito, -te ordeno que-, como en algunos de los ejemplos de Lapesa, o en el famoso de Fray Luis propuesto por Bello "No digas..."), pero sólo en la primera oración lo expresado en la causal constituye el motivo o la razón, "la causa" de que el hablante "ordene (mande, etc. ) que ..." ; en la segunda, el motivo para el hablante sigue siendo probablemente el mismo, "el miedo al calambre", pero la razón aducida afecta al oyente, es, como dijimos, "una razón para el oyente". En cuanto a la denominación, establecidos los valores, usaremos el término "suboración", pero también el simple oración o proposición, indistintamente. 
diferencias?. Para ello tomamos como punto de partida la colocación de la oración de gerundio dentro del periodo causal, que (aún en la duda de que sea el mejor) supone uno de los criterios más objetivos.

Atendiendo, pues, a las distintas posiciones que ocupa la causal y a los tipos de construcción, observamos lo siguiente:

\section{POSICIÓN POSPUESTA:}

En esta posición la oración causal con gerundio la encontramos tanto en construcción conjunta como en construcción absoluta, y siempre la oración de gerundio aparece como única causal.

\subsection{Construcción conjunta:}

En este tipo de estructura el sujeto común puede aparecer explícito (como podemos ver en el tercer ejemplo) o, como ocurre más frecuentemente, elíptico y marcado por las desinencias del verbo personal. En el aspecto semántico observamos cómo en la mayoría de los ejemplos recogidos el verbo de la oración de gerundio pertenece al campo conceptual de los llamados verbos de voluntad o lengua, aunque no siempre:

E esto fazemos entendiendo que es seruiçio de nuestro sennor el rey e nuestra pro, commo quiera que era en nuestra hermandad puesto de non coger en ella a ningun rico ome (Doc. 18, ls. 20-22, f. 1r).

E vse comigo como pertenesçe a la grandeza de la çibdad e a vosotros, sennores, mayormente veyendo que en la çibdad de Córdoua se contentarian con la mitad de lo que aqui se faze (Doc. 793, 1s. 10-13, f. 2r).

...el otro dia commo amanesció, los portogueses fueron a correr a Villa nueva, pensando que non estaua más gente de aquellos seys de cauallo (Doc. 218, 1. 21).

Las diferencias significativas conllevan también distinciones de otro tipo. Así, en el primer caso el contenido semántico del gerundio, o el propio gerundio, podría eliminarse ${ }^{10}$, sin que se alterara sensiblemente el contenido "causal" que subyace en la estructura global: "entendiendo que es seruiçio de nuestro sennor el rey" sería equivalente a "porque es seruiçio de nuestro sennor el rey", e incluso a esta otra" ${ }^{11}$ " "siendo servicio de nuestro señor el rey" . Y algo similar se podría decir del segundo ejemplo. Pero no del tercero, pues las correrías se vieron frustradas, al haber más gente de aquellos "seys de cauallo" que pensaban. Aunque los distintos matices significativos vienen marcados por el contexto.

En cuanto al tipo de causa indicado vemos cómo las diferencias están determinadas, en líneas generales, por la modalidad del verbo de la "principal", de modo que en el primer ejemplo estaríamos ante una causal de la enunciacion, cuyo verbo de voluntad se halla

9 Para Lapesa (1978) el orden de colocación de la causal es indicativo del tipo de causa, de modo que, por ejemplo, la posición antepuesta ya es indicativa de causa conocida.

${ }^{10}$ Evidentemente con modificaciones, como introducir la completiva del gerundio por una conjunción causal.

11 Igualmente correcta sintácticamente, pero eliminando el significado del primitivo gerundio, sustituido por el verbo ser. 
implícito, mientras que en los dos siguientes nos encontramos ante causales del enunciado. Sin embargo también aquí1 ${ }^{12}$ cabría preguntarse si, en el segundo ejemplo, la verdadera causa es "veyendo que en la çibdad de Córdoua se contentarían ..." o simplemente "porque en la çibdad de Córdoua se contentarían ...".

También aparecen algunos ejemplos en los que es el verbo de la oración "principal" el que pertenece a esa esfera semántica, sobre todo verbos de mandato o similar, que pueden aparecer explícitos o elípticos:

$\mathrm{E}$ a otra alguna nin algunas personas non dedes nin paguedes nin consintades dar nin pagar los dichos maravedís e otras cosas nin parte dellos, saluo al dicho Alfonso Garçia de Madrid o a quien su poder ouiere, çertificándovos que lo que de otra guisa diéredes e pagáredes que a vosotros e a vuestros bienes me tornaré por ello e vos lo faré pagar otra vez. (Doc. 651, ls. 13-15).

En estos casos lo expresado en la proposición causal actúa como causa, motivo o razón para mandar (ordenar) que se cumpla (o no) lo que se pide ${ }^{13}$, igual que en el primer ejemplo.

Este tipo de construcción que acabamos de ver se repite con relativa frecuencia en un determinado grupo de documentos, Provisiones reales, aunque alternando las oraciones de gerundio con otras formas de expresión, como vemos en este otro texto de la misma época:

E non recudades con ellos nin con parte dellos a otra persona alguna, sy non sed çiertos que cualesquier maravedís que de otra guisa diérdes e pagardes vos los faré pagar otra vez por vosotros e por vuestro bienes. (Doc. 636, 1s. 12-14).

Pero además comprobamos que este tipo de oración causal con gerundio, que señala también una causa para que el oyente no incumpla lo ordenado ${ }^{14}$, aparece, en los textos que estudiamos, hacia mediados del siglo $\mathrm{XV}$, y recuerda bastante a construcciones similares que se documentan en épocas anteriores en este mismo corpus, aunque antes la oración causal aparecía introducida por una partícula conjuntiva, fundamentalmente ca o que, partículas que empiezan a ser cada vez menos frecuentes en este tipo de construcción precisamente a partir de esa época's:

E defiendo firmemente que ninguno nin ningunos non sean osados de yr nin de pasar al dicho conçeio de Éçija contra esta merçed que les yo fago nin contra ninguna cosa della, ca qualquier o qualesquier que lo fiziese pecharme yan en pena mill maravedis ... (Doc. 32, ls 14-16).

\footnotetext{
12 En la línea de lo expuesto anteriormente de igualdad semántica de conocimiento de un hecho y realidad del mismo.

${ }^{13}$ Vid. Bello, A (1970); Lapesa, R (1978); Santos, L (1982 ); Zaragueta (1950: 57); etc.

${ }^{14}$ Ver lo indicado arriba en nota 8.

15 En cuanto a la relación entre estos dos hechos (aumento de construcciones con gerundio y disminución de oraciones con esas partículas y verbo en forma personal), si la hay, y cuál pudo ser el elemento desencadenante, pérdida progresiva de partícula o aumento de la presencia del gerundio, quizás por influencia culta, no podemos determinarlo ahora.
} 
Observamos también que en esta posición, la oración de gerundio, al igual que las causales introducidas por conjunción (excepto ca y que), puede funcionar como causal de otra causal:

E otrosy porque los dichos perlados e ricos omes e procuradores de las çibdades e villa e lugares que estauan aquí en el dicho ayuntamiento nos otorgaron la alcauala por seys annos entendiendo que esto era lo con que nos podían seruir para la costa que avemos a fazer en mantener Algezira e a los otros castiellos fronteros e [... ] nos, por les fazer merçed, tenemos por bien de mandar que se non coja alcauala ninguna de los cauallos nin de las armas ... (Doc. $51,1 \mathrm{~s} .28-31, \mathrm{f} .2 \mathrm{r}$ )

El ejemplo, como en otros casos, se presta a posibles interpretaciones. En el periodo causal completo la oración de gerundio aparece como un inciso explicativo, pero realmente lo expresado en ella, "entendiendo que esto era lo con que nos podían servir", es la causal real de lo indicado en la primera causal introducida por porque.

\subsection{Construcción absoluta:}

En estas construcciones la causal con gerundio suele indicar una explicación o aclaración a algo dicho anteriormente. En estos casos se suele hablar de relativa independencia oracional, independencia que "tiene su confirmación en la tendencia general a aislarlas por medio de pausas, cualquiera que sea el lugar que ocupe en la oración compuesta" (RAE, 1976: 492) ${ }^{16}$. Pero, como se ha dicho, habría que especificar con respecto a qué elementos.

En el caso de que se trate de un gerundio compuesto comprobamos que el sujeto, que se halla expreso, en vez de ir pospuesto, como suele ser lo general en este tipo de construcción en el español moderno ${ }^{17}$, aparece intercalado entre las dos formas, siguiendo la estructura habitual de las construcciones medievales:

...et que fasta agora non avíades puesto ningunas maguer que por ellos auíades seydo requeridos, por lo qual la tierra non estaua g(uardada) et que podría venir danno en ella, de lo qual nosotros somos maravillados, auiendo vosotros dicho que auíades puesto las dichas guar(das susodi)chas e non están acá ninguna dellas. (Doc. 367, 1s. 6-8).

\section{POSICIÓN ANTEPUESTA:}

Es la posición en que aparecen con menor frecuencia las oraciones causales con gerundio, y los ejemplos recogidos son todos casos de construcción conjunta.

Desde el punto de vista significativo, suele expresar causa conocida, o por lo menos hace referencia a algo expresado con anterioridad, ya sea directamente o a través de otra causal dependiendo de ella, como vemos en:

Sabed que yo so ynformado que en la guarda desa çibdad non se pone aquella diligençia que cunple. E consyderando cuanto dapnno podría recreçer por la dicha çibdad non estar a buen

16 Sin embargo esa última afirmación habría que matizarla, pues la separación entre pausas es, como veremos, mucho más evidente en determinadas posiciones, sobre todo intercalada.

17 Vid. RAE (1976: 492); Gili Gaya (1978: 193), etc. 
recabdo, por la presente mando a don Lope Áluarez. Comendador mayor, e a vos [... ] que tomen conseguo a vos, la dicha mi justiçia... (Doc. 655, 1s. 2-5),

$\mathrm{Y}$, al igual que cuando se trata de oraciones causales introducidas por conjunción, también con gerundio la oración causal puede aparecer resumida en una locución preposicional, del tipo por ende, por esto, por ello, etc.:

Otrosi, veyendo la gran tempestá que malpocado este anno ouo en los panes, en que auemos todos tomado muy grant danno, por esto acordamos que los judios atiendan por todas las debdas que les deuemos en toda la hermandat así de pan commo de dineros e de pannos e de sobrepannos .... (Doc. 18, 1s 24-27, f. 2r).

\section{POSICIÓN INTERCALADA:}

Es la estructura más frecuente, y aunque la mayoría de los ejemplos recogidos son de construcción conjunta, también se documentan algunos casos de construcción absoluta. Por otro lado, observamos cómo en esta posición la oración de gerundio puede aparecer como única causal o bien hallarse en coordinación con otras causales.

\subsection{Una sola causal}

Cuando la oración de gerundio aparece como única causal, la podemos encontrar intercalada en la "causada" entre el sujeto y el verbo en forma personal, o bien entre el verbo y el complemento (o los complementos), tal como ocurre en los casos de causales con conjunciones:

\subsubsection{Entre el sujeto y el verbo}

En esta posición todos los ejemplos recogidos aparecen en construcción conjunta. Pero además el sujeto, que suele ser un pronombre personal, aparece una sóla vez, y como decimos precediendo al gerundio ${ }^{18}$.

También comprobamos cómo en este caso casi siempre la oración causal hace referencia a algo dicho anteriormente ${ }^{19}$, por lo que podríamos decir, en líneas generales, que estamos ante casos de causa conocida:

E todos los otros procuradores de las dichas çibdades e villas me pidieron que les mandase dar las espensas que acá auían fecho por el tienpo que a(cá) auían estado. Et yo, viendo que me pedían derecho, tóuelo por bien ... (Doc. 127, 1s. 6-7)

E yo, veyendo que uno de los mayores peligros que podía auer agora en estos mis regnos era esto, oue mi acuerdo con el ynfante don Ferrando, mi hermano, e con los mis tutores e con los otros perlados e caualleros e escuderos e consejeros de las çibdades (Doc. 140, 1s. 11-13).

18 Esta estructura es, igualmente, una de las más usadas en los textos literarios, según se desprende de los ejemplos que encontramos en Kretschmann (1936: 78-80) y lo mismo parece deducirse de los generales - la mayoría causales- señalados por Muñio Valverde (1995: 20-21).

19 De ahí que también aquí el verbo en gerundio se inscriba semánticamente en el campo de los verbos de entendimiento: teniendo, pensando, creyendo, etc., que "exigen" un complemento directo (o aditamento) que de alguna manera hace referencia a algo expresado anteriormente. 
E yo, queriendo proueer çerca dello, por esta mi carta vos mando que de aquí adelante vos nin algunos de vos no vos non vos (sic) entremetades a esecutar nin executedes nin fagades executar los tales mandamientos nin ... (Doc. 614, 1s. 17-18).

Como puede observarse, además, en todos los ejemplos lo expresado en la oración de gerundio es siempre una causa expuesta por el hablante, que sirve de justificación ante sí, y sobre todo ante los demás, de lo señalado en la otra oración, la causada, que generalmente suele ser una orden, un acuerdo o similar, etc.

\subsubsection{Entre el verbo y el complemento:}

Aquí encontramos ejemplos tanto de estructura conjunta como de construcción absoluta, si bien los primeros son más frecuentes. Generalmente, como venimos observando, se trata de proposiciones insertas en una oración cuyo verbo principal es un verbo de voluntad (que, ya lo hemos repetido, exige complementación), mientras que lo expresado en la causal es la causa o razón de lo ordenado y también el motivo de la orden:

\subsubsection{Construcción conjunta:}

El sujeto, como es habitual en este tipo de construcción, puede no aparecer de forma explícita, y, sobre todo, se da la elipsis cuando entre el verbo conjugado y el gerundio aparece algún complemento con formas personales, como vemos en el siguiente texto:

Et otrosí ponemos entre nos, teniendo que es gran seruiçio de Dios e del rey e guarda de la tierrra, que todos los terquelos de las eglesias de la hermandat destos dos annos pasados e de oganno que los tomemos para ayuda, a guarda de la mar. (Doc. 18, 1s. 8-10, f. 2r).

Y también en esta posición habría que considerar los siguientes ejemplos, aunque pertenecientes al estilo indirecto:

Fagovos saber que entendiendo ser asy conplidero a mi seruiçio e al bien e pro común [...] yo por una mi carta firmada de mi nonbre e sellada con mi sello acreçenté vna alcaldía mayor en esa çibdad de más de la otra que fasta aquí en ella auía ... (Doc. 755, 1s 2-4).

Ya sabedes commo yo, entendiendo ser asy conplidero a seruiçio de Dios e mío e a onor de la corona real de mis regnos e a bien [ ... ] vine por mi persona en estas partes con entençión de fazer guerra contra los dichos moros... (Doc. 693, 1s. 14-17).

Si comparamos estos dos textos, que además son muy similares, podemos comprobar cómo el sujeto puede aparecer inmediatamente después de la oración de gerundio o bien precediendo a éste, pero se trata simplemente de diferencias estilísticas ${ }^{20}$, variaciones formularias debidas a los diferentes escribanos.

${ }^{20}$ El primero de los ejemplos procede de un Albalá de Enrique IV, emitido en Segovia el 12 de octubre de 1463, el segundo es una Provisión también de Enrique IV fechada en Jaén el 15 de septiembre de 1456. 


\subsubsection{En construcción absoluta:}

Ya decíamos antes que este tipo de construcción es mucho menos frecuente ${ }^{21}$. De hecho sólo hemos encontrado un ejemplo:

Sepades que plaziendo a Nuestro Sennor yo quiero entrar a tierra de los moros enemigos de nuestra santa fe católica a los talar e fazer algunas otras cosas conplideras a seruiçio de Dios e mío ... (Doc. 689, 1s. 3-4)

Y en él el significado de la oración de gerundio podría interpretarse tanto causal como condicional, si bien el contenido del último ejemplo del apartado anterior, con cuyo documento se halla relacionado el de este texto, nos permite pensar más bien en un posible valor causal ${ }^{22}$.

\subsection{Varias causales:}

La oración de gerundio puede hallarse en coordinación con otras causales o con otras oraciones o proposiciones pertenecientes al campo semántico de la causalidad, proposiciones que pueden venir expresadas también por un gerundio o bien introducidas por una conjunción y un verbo en forma personal, o por cualquier otra forma de expresión de la causalidad. En todos los ejemplos que hemos documentado en nuestro corpus estas oraciones se hallan intercaladas entre el sujeto y el verbo, y también en todos ellos estamos ante el tipo de construcción conjunta.

3.2.1 Varias causales coordinadas, expresadas todas con verbo en gerundio, tenemos en el siguiente texto:

E yo, veyendo que era mio deseruiçio e grant danno e menoscabo de toda la mi tierra, queriendo e amando el aprovecho comunal de los que biuen en los mios regnos, tengo por bien de mandar fazer ordenamiento en cada una de las comarcas de mios regnos sobre estas cosas en la manera que aquí dirá. (Doc. 57, 1s. 19-23);

donde los gerundios aparecen siempre expresos (no así la conjunción que esperaríamos antes de "queriendo", aunque éste es un fenómeno relativamente frecuente en este tipo de documentos) por aportar cada uno un contenido verbal distinto. Pero también puede ocurrir, sobre todo en formas verbales compuestas donde el contenido semántico de la perífrasis lo aporta el infinitivo, que el gerundio en función de auxiliar del sintagma verbal se elida, si ya ha sido expresado anteriormente en otra oración con la que esta segunda aparece coordinada copulativamente. Así:

e el sobredicho Bartolomé Sánchez, queriendo dannar este camino real e dar manera a los otros commo robasen los derechos de esta villa, lleuolos por ally ... (Doc. 626, 1s. 29-30).

En cualquiera de los casos, el sujeto sólo aparece expreso delante del primero de ellos. En el plano semántico sólo el contexto permite diferenciar entre causa conocida o no

${ }^{21}$ Tampoco en los textos literarios parece que sea construcción usual, pues si bien Kretschmann (1936: 80) dice que no es una construcción rara, los ejemplos aducidos, en su mayoría, no tienen realmente significado causal.

22 Interpretado como 'porque plaze a Dios' estaríamos ante la justificación, sin más, de la guerra; como 'si plaze a Dios' la situación se atenúa. O tal vez estaríamos en esa zona indeterminada considerada como causal-hipotética. Vid. L Contreras (1959). 


\subsubsection{Varias causales coordinadas con gerundio y cualquier otra forma de expresión causal ${ }^{23}$ vemos en:}

...el qual, por seruiçio mío e veyendo que asy conplía, ge la ouo de renusçiar e enbió mandar ... (doc. 829, ls. 14-16, f. 1r);

E yo, catando los muchos seruiçios e bonos que los de la dicha villa fizieron a los reyes onde yo vengo et sennaladamente al dicho rey mi padre en muchos menesteres que ouo, e porque ellos ayan con qué me seruir más conplidamente, tengo por bien e mando que les sea guardada la dicha carta de las dichas franquezas .... (Doc. 54, 1s. 12-14).

o, como aparece en el siguiente texto, donde encontramos varias causale ${ }^{24}$ expresadas de $^{2}$ diversas formas, algunas de ellas con valor estilístico, para evitar la continua repetición de conjunciones:

Yo, porque el conçeio de Éçija me lo enbiaron pedir por merçet, e por muchos seruiçios que me fizieron e fazen de cada día e porque la villa se pueble meior $e$ finque sosegada, e auiendo voluntat de les fazer bien e merçet e porque se guarden de aquí adelante de non fazer mal, perdónoles la mi justiçia e la pena que yo pudía auer contra los vezinos e moradores de Éçija ... (Doc. 24, 1s. 6-10).

Todas ellas indican, como puede verse, la causa o razón de lo indicado en la "principal", que además, lleva siempre el verbo en forma personal.

Una construcción especial, dentro de este grupo, vemos en determinados casos en que la oración causal con gerundio aparece precedida de un sintagma preposicional, las tradicionales partículas ilativas, en función de enlace, o como verdadero complemento circunstancial de causa, que siempre es "por ende" y que resume toda una serie de oraciones anteriores, generalmente con significado causal, y a las que, en la mayoría de los casos, también suele hacer referencia la oración de gerundio. Así lo vemos en :

Porque es natural cosa que todo ome que bien faze quiere que gelo lieuen adelante e que se non olvide nin se pierda que commo quiere que cansse e mingue el curso de la vida deste mundo aquello es lo que finca en remenbrança [...] Et por non caher en olvido lo mandaron los reyes poner en escripto [...]. Por ende nos, catando esto, queremos que sepan por este nuestro priuillegio los que agora son e serán daquí adelante, commo nos don Fernando, por la graçia de diios rey de Castiella, ... (Doc. 10, 1s. 1-4).

Et, sennores, yo, por quanto vi que seyendo la cosa en cargo de algunos omes buenos desta villa que se non faría commo era menester, quel seruiçio del rey nuestro sennor non sería conplido commo deuía, asy commo de ante se fazía nin la onrra e guarda vuestra e de

23 No podemos entrar ahora a debatir la cuestión planteada por algunos autores sobre el valor de proposición o adverbio que la causal tendría en estos casos en que aparece coordinada a un supuesto adverbio "por seruiçio mio", que evidentemente tiene características específicas, pues este tipo de construcción, "por + sustantivo" con valor causal, sólo es posible cuando el sustantivo es un posverbal, o existe un verbo de la misma familia léxica, con lo que pervive en la raíz el significado léxico del verbo del que procede o con el que se halla relacionado (en este caso servir), y, por tanto, puede equipararse a "por + infinitivo", e incluso a un gerundio.

${ }^{24}$ Es verdad que algunas de ellas se interpretarán como finales, pero creo que, desde el punto de vista semántico, estamos en esa línea poco precisa en que causa y fin suelen coincidir. 
nosotros atan poco [...] Por ende yo, veyendo todo esto, tireme afuera et algunos desta villa tomaron este encargo porque ganassen este denero sus fijos e sus parientes ... (Doc. 379, ls. 5-10).

Pero el sintagma preposicional y la oración de gerundio también pueden ser independientes tanto semántica como funcionalmente, aunque, como en otros casos, el nexo coordinante no aparezca explícito:

Por quanto por algunas cosas conplideras a mi seruiçio et pro común de mis reynos, mi merçed et voluntad es de prorrogar et alargar la tregua e sobreseymiento de guerra que por mi mandado agora está asentada et firmada entre mis reynos et el rey et moros del reyno de Granada de aquí a en fyn del mes de março deste anno fasta el día que sus mensajeros que agora comigo están en mi corte sean por mí despachados [...] Por ende, confyando de la prudençia e discreçión de vos [...] por la presente vos do liçençia et plenaria abtoridat e facultad para que por mí et en mi nonbre [...] podades la dicha tregua que ansy fasta en fin de março está asentada, prorrogalla, asentalla, firmalla et juralla con el dicho rey et reyno de Granada ... (Doc. 728, 1s. 20-26).

\section{CONCLUSIONES:}

De lo visto hasta aquí podemos deducir las siguientes conclusiones:

En el aspecto semántico las oraciones o, en terminología de Lapesa, suboraciones de gerundio pueden expresar el mismo tipo de causa que cualquier proposición introducida por una partícula causal: causa conocida, causa desconocida, causa del oyente, aunque la mayor frecuencia de uso responde a la primera ${ }^{25}$. Y también aquí, en algunos casos, resulta difícil distinguir si estamos ante una causa de lo dicho o una causa de decir, o ante ambas cosas a la vez, por la ambivalencia que presentan algunos contextos, Sin embargo éste no es un problema sólo de esta época o de estos textos especialmente, sino que se da también en el español de hoy.

En cuanto al significado de los verbos en gerundio, destaca de modo especial la pertenencia de la mayoría de ellos al campo conceptual de los verbos de entendimiento, o lengua. Y en ello coincide con los usos en textos literarios (Krestchmann, 1936: 78; Muñio Valverde, 1995: 107). Este hecho (que explica su mayor frecuencia de uso para la causa conocida, o a la inversa) permite pensar que los gerundios en este tipo de construcciones se deben a usos cultos (pero los datos con que contamos no nos permiten de momento un estudio diastrático que nos llevara a conclusiones fiables).

Desde el punto de vista sintáctico la relación que se establece entre la suboración causal de gerundio y la causada es, igual que con las conjunciones, en general, de subordinación, ya aparezca el verbo de esta última explícito o se halle elíptico, como ocurre en el caso de las "causales de decir", o cuando el verbo de la "principal" aparece en imperativo u otra forma con valor de mandato. Sin embargo surge la duda de si determinadas oraciones de gerundio (que igualmente pueden aparecer con conjunción), las que hemos llamado "causa del hablante y del oyente"26, expresan "una circunstancia del verbo dominante". De no ser

${ }^{25}$ Según Kretschmann (1936: 79), en los textos literarios tiene mayor uso para la causa desconocida.

${ }^{26}$ Ver lo indicado en $\& 1.1$ y nota 8. 
así, como creemos (al menos del verbo expreso), tampoco podríamos hablar con seguridad de subordinación.

En cuanto al tipo de construcción, aparece con gran predominio la construcción conjunta, y ése es también el uso más frecuente en los textos literarios (Krestchmann, 1936: 79)

En el plano formal (pero con implicaciones sintáctico-semánticas), la oración de gerundio puede ocupar diferentes posiciones dentro del periodo causal, pospuesta, antepuesta e intercalada, siendo esta última la que ofrece mayor frecuencia de uso, sobre todo intercalada entre el sujeto y el verbo, es decir, cuando la causa se quiere destacar. En este aspecto las construcciones con gerundio superan las posibilidades de algunas proposiciones conjuntivas que presentan ciertas restricciones ${ }^{27}$. Quizás también por ello su uso aumente conforme avanzamos en la época bajomedieval, pero tendremos que comprobarlo con otro tipo de textos e incluso en épocas posteriores.

\section{BIBLIOGRAFÍA:}

Badía Margarit, A. (1964): "El gerundio de posterioridad", Presente y futuro de la Lengua Española, vol. II, pp. 287-295.

Bassols de Climent, M. (1981): Sintaxis Latina, Madrid, Consejo Superior de Investigaciones Científicas.

Bastardas Parera, J. (1955): Particularidades sintácticas del latín medieval, Barcelona, Consejo Superior de Investigaciones Científicas.

Bello, A. y CuERvo, R. J. (1970 [19 ]): Gramática de la lengua castellana, Buenos Aires, Ed. Sopena.

Bobes NAVES, Ma C. (1975): "Sistema, norma y uso del gerundio castellano", Revista Española de Lingüística, 5, 1, pp 1-34.

Bouzet, J. (1953): "Le gérondif espagnol dit 'de posteriorité”", Bulletin Hispanique, vol. 55, pp. 349-374.

Contreras, L. (1959): "El periodo causal hipotético con "si"”, Boletín de Filología de la Universidad de Chile, vol . II, pp. 355-359.

GALMÉS DE FUENTES, A. (1996): Influencias sintácticas y estilísticas del árabe en la prosa medieval castellana, Madrid, Gredos.

GILI GAYA, S. (1978): Curso superior de sintaxis española, Barcelona, Bibliograf.

GUTIÉRREZ ARAUS, Ma L. (1978): Estructuras sintácticas del español actual, Sociedad General Española de Librería, Madrid.

27 Así, en el corpus utilizado, ca y pues no suelen utilizarse para encabezar oraciones causales coordinadas, y que sólo cuando la otra causal va encabezada por porque. Tampoco ca se emplea cuando la causal va antepuesta a la principal, y, por el contrario, la forma commo sólo la hemos encontrado como introductora de causales en esta posición. (Mendoza, 1985: 428). 
HALlebeEK, J. (1998): "Sintaxis y uso del gerundio en español actual”, Lingüística Española Actual, XX, 2, pp. 175-215.

KRETSCHMANN, W. (1936): Die kausalsätze und kausalkonjunktionen in der altspanischen Literatursprache, Hamburgo (Inaugural-Dissertation).

LAPESA, R. (1978): "Sobre dos tipos de subordinación causal", Estudios ofrecidos a Emilio Alarcos Llorach, vol. III, pp. 173-205.

LYER, ST. (1932): La syntaxe du gérondif dans le "Poema del Cid"", Revista de Filología Española, XIX, pp. 1-46.

LYER, ST. (1934): Syntaxe du gérondif et du participe présent dans les langues romanes, Paris, Librairie E. Droz.

MARCos MARÍn, F (1980): Curso de Gramática Española, Madrid, Cincel.

MENDOZA ABREU, J. Ma (1985): el sistema conjuntivo causal en la documentación del Concejo de Écija (siglos XIII-XV). Tesis Doctoral inédita. Universidad de Sevilla.

Menéndez Pidal, R. (1976): Cantar de Mio Cid. Texto, Gramática y Vocabulario, Madrid, Espasa-Calpe.

MosteIRo LouZAO, M (1998): "La relación modo-temporal en la expresión de la causa en el "Poema del Mio Cid"”, Verba, vol. 25, pp. 243-291.

Muño VAlVERde, J. L. (1995): El gerundio en español medieval (S. XII-XIV), Málaga, Editorial Ágora.

REAL ACADEMIA ESPAÑOLA (1976): Esbozo de una nueva gramática de la lengua española, Madrid, Espasa-Calpe.

SANTOS Río, L. (1982): "Reflexiones sobre la expresión de la causa en español", Studia Philologica Salmanticensia, vol. 6, pp. 231-277.

Zaragüeta, J. (1950): Filosofía y vida, Madrid, Consejo Superior de Investigaciones Científicas. 